\title{
The Design of the Puruk Cahu City Health Office Filing Information System
}

\section{Perancangan Sistem Informasi Pengarsipan Kantor Dinas Kesehatan Kota Puruk Cahu}

\author{
Hanafi Fajar ${ }^{1}$, Esi Putri Silmina ${ }^{2}$ \\ \{hanafifajar98@gmail.com¹﹎,esiputrisilmina@unisayogya.ac.id $\left.{ }^{2}\right\}$
}

Program Studi Teknik Informasi, Fakultas Sains dan Teknologi, Universitas Aisyiyah Yogyakarta

\begin{abstract}
The advancement of computerized-based information technology which is able to play an important role as a tool in archiving documents such as incoming and outgoing mail, data processing, and can help solve small problems to very complex problems or even in decision support. At the Puruk Cahu City Health Office, the archiving of incoming and outgoing letters is still manual with notes in the agenda book which makes it difficult to search for letter files. This aims to create a system for collecting incoming and outgoing mail to make it easier for mail archiving and mail search. The research method used is the method of observation, interviews, and literature study. With the integrated design of the archiving information system at the Puruk Cahu City Health Service Office, it will be able to help the performance of the Puruk Cahu City Health Office employees.
\end{abstract}

Keywords - Database; Information System; Management; Filing

Abstrak - Kemajuan teknologi informasi yang berbasis komputerisasi mampu memegang peranan penting sebagai alat bantu dalam pengarsipan dokumen seperti surat masuk dan surat keluar, pengolahan data, serta dapat membantu memecahkan masalah yang kecil sampai dengan masalah yang sangat kompleks ataupun dalam penunjang keputusan. Pada Kantor Dinas Kesehatan kota Puruk Cahu dalam pengarsipan surat masuk dan surat keluar masih manual dengan dicatat ke dalam buku agenda yang mengakibatkan sulitnya dalam pencarian berkas surat. Hal ini bertujuan untuk membuat system pengarsiapan surat masuk dan surat keluar untuk memudahkan dalam pengarsipan surat dan pencarian surat. Metode penelitian yang digunakan adalah metode observasi, wawancara, dan studi Literatur. Dengan adanya Perancangan sistem informasi pengarsipan pada Kantor Dinas Kesehatan Kota Puruk Cahu yang terintegrasi akan dapat membantu kinerja pada pegawai Dinas Kesehatan Kota Puruk Cahu.

Kata kunci - Database; Sistem Informasi; Pengelolaan; Pengarsipan

\section{PENDAHULUAN}

Setiap institusi, organisasi, dan lembaga pemerintahan tidak dapat lepas dari data dan pengarsipan. Data ini berperan sebagai sumber informasi dan dasar bagi pengambilan keputusan dalam rangka menyelanggarakan fungsi organisasi tersebut untuk melayani publik [1]. Pengelolaan arsip yang tepat mengikuti peraturan dan kaidah kearsipan tentunya akan memberikan manfaat signifikan bagi institusi, organisasi, dan lembaga pemerintahan tersebut. Arsip yang lengkap, autentik, dan kredibel akan mendukung terlaksananya fungsi organisasi tersebut dalam rangka penilaian performansi kinerja, pertanggungjawaban kinerja, dan pelayanan publik [2].

Arsip berfungsi untuk menampilkan informasi dan data secara cepat dan akurat kepada yang membutuhkan. Sistem pengarsipan dapat dikatakan baik.Jika waktu penyimpanan atau pengarsipan yang dibutuhkan dapat ditemukan kembali secara akurat dan cepat, maka pengorganisasian kearsipan sangat efektif dan sistematis, karena sistem pengarsipan tidak jauh dari kegiatan penjadwalan pengarsipan dan kegiatan lainnya., seperti penemuan. kembali [3].

Pengelolaan surat masuk dan surat keluar merupakan salah satu tugas yang harus dijalankan agar proses layanan menjadi maksimal [4]. Informasi yang terekam merupakan bukti dan dokumen atau kenangan dari organisasi yang bersangkutan. Surat merupakan salah satu media komunikasi terpenting dalam institusi, perusahaan dan bentuk organisasi lainnya, serta dapat berkomunikasi baik dengan pihak eksternal maupun internal [5]. Segala sesuatu yang berhubungan dengan kegiatan organisasi kedinasan selalu dituangkan dalam bentuk surat [6]. Surat Keluar adalah surat lengkap yang diterbitkan oleh instansi atau lembaga lain (tanggal, nomor, distempel dan ditandatangani oleh petugas yang berwenang), mulai dari surat penerimaan, pencatatan surat masuk dan surat keluar, dan pengiriman surat masuk dan keluar.Data hanya disimpan di file kerja, yang akan menyebabkan keterlambatan dalam proses pencarian data surat dan membuat laporan menjadi tidak valid. Oleh karena itu penulis ingin membangun sebuah rancangan sistem, yaitu perancangan sistem pengarsipan surat masuk dan surat keluar pada Kantor Dinas Kesehatan Kota Puruk Cahu.

Permasalahan yang muncul saat menyimpan data adalah masih kurangnya pengorganisasian dan ketidakefisienan, karena belum adanya tempat penyimpanan data yang terintegrasi [7]. Tujuan dari penelitian ini adalah untuk 
mempermudah proses penomoran, representasi layanan, dan mempercepat pengolahan laporan kearsipan berbasis standar, sehingga dapat mencegah hilangnya data arsip secara lebih cepat, tepat, dan akurat [8]. Pelayanan, dinas membutuhkan sistem pelayanan Dinas Kesehatan Kota Pruukkahu untuk meningkatkan kinerja penyedia layanan Dinas Kesehatan Kota Pruukkahu, meningkatkan kualitas pelayanan peralatan, menjadikannya sistem komputer, dan memajukan pendataan/Arsip [9].

\section{METODE}

Adapun metode penelitian ini adalah teknik observasi, studi literatur, dan wawancara. Observasi dilakukan oleh peneliti secara langsung di lapangan sekaligus melakukan wawancara dengan pegawai di bidang Kepegawaian Dinas Kesehatan Kota Puruk Cahu. Sementara studi literatur dilakukan oleh peneliti dengan membaca referensi dari paper, jurnal, dan penelitian lain yang terkait dengan pengarsipan dan sistem informasi. Berikut merupakan penjelasan detail terkait metode yang digunakan untuk mengumpulkan data, yaitu:

Observasi

Metode observasi atau yang sering disebut pengamatan adalah salah satu jenis teknik pengambilan dan pengumpulan data dengan cara melakukan pengamatan langsung di lapangan. Peneliti akan berada di lokasi pengamatan secara langsung guna memperoleh fakta-fakta atau bukti yang valid sebagai bahan dalam penelitian yang akan diajukan. Peneliti akan menuliskan semua informasi terkait sesuai dengan kondisi riil yang mereka lihat di lapangan selama penelitian.

\section{Wawancara}

Wawancara merupakan sebuah percakapan (conversation) yang memiliki maksud dan tujuan tertentu. Yang namanya percakapan tentunya melibatkan dua belah pihak yakni pewawancara (interviewer) yaitu pihak yang memberikan sejumlah pertanyaan dan narasumber atau terwawancara (interviewee) yaitu pihak yang akan menjawab pertanyaan yang telah diajukan. Wawancara dilakukan secara langsung dan bertatap muka.

\section{Study literatur}

Studi literatur pada hakikatnya adalah langkah awal dalam metode pengumpulan data. Studi literatur ialah salah satu teknik pengumpulan data dengan cara mencari referensi data dan informasi melalui dokumen yang terkait dengan topik penelitain dan dapat dijadikan sebagai referensi dalam penelitian tersebut [10].

\section{HASIL DAN PEMBAHASAN}

Use Case analisis pertama dilakukan dengan menerjemahkan hasil observasi sistem berjalan ke dalam use case. Atas beberapa alasan use case dianggap cukup mudah menerjemahkan kondisi sistem sehingga dapat diidentifikasi masalah yang muncul maupun potensial masalah. Dengan demikian selanjutnya dapat diusulkan perbaikan system yang efektif untuk membangun system yang sesuai dengan kebutuhan.

Adapun sistem manajemen informasi pengarsipan secara elektronik dan menggunakan otomasi dengan komputer dijelaskan sebagai berikut.

\section{A. Diagram sistem berjalan}

Sistem existing yang berjalan saat ini dianalisis menggunakan program Visual Paradigma for Unifield Modeling Language (UML) Enterprice Edition untuk mengilustrasikan prosedur dan proses yang berjalan di kondisi saat ini (current condition), sebagai berikut :

Alur use case surat masuk 
Procedia of Engineering and Life Science Vol. 1. No. 2 Juni 2021

Seminar Nasional \& Call Paper Fakultas Sains dan Teknologi (SENASAINS 2 ${ }^{\text {nd }}$ )

Universitas Muhammadiyah Sidoarjo

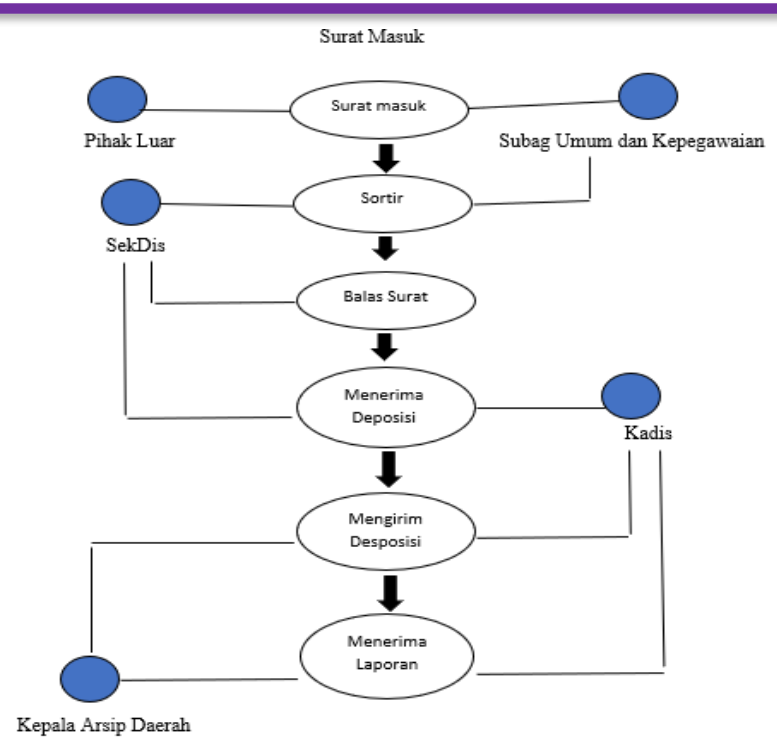

Gambar 1. Use Case Diagram Surat Masuk

Gambar 1 menunjukkan urutan dan unsur-unsur dalam Use Case Diagram surat masuk yang berjalan pada kondisi saat ini antara lain sebagai berikut, yakni:

A. Satu keseluruhan sistem yang meliputi semua rangkaian pelaporan surat masuk di Kantor Dinas Kesehatan Kota Puruk Cahu, Kabupaten Murung Raya, Provinsi Kalimantan Tengah.

B. Terdapat lima aktor yang terlibat dalam kegiatan pengarsipan yaitu pihak luar, sekdis, subag umum dan kepegawaian, kadis, dan kepala.

C. Terdapat enam tahapan use case yang dikerjakan oleh aktor yaitu menerima surat masuk, menyortir dan menyusun laporan yang berisi surat masuk, menggabungkan data, melakukan audit arsip, menerima dan mengesahkan laporan pengarsipan.

Alur use case surat keluar

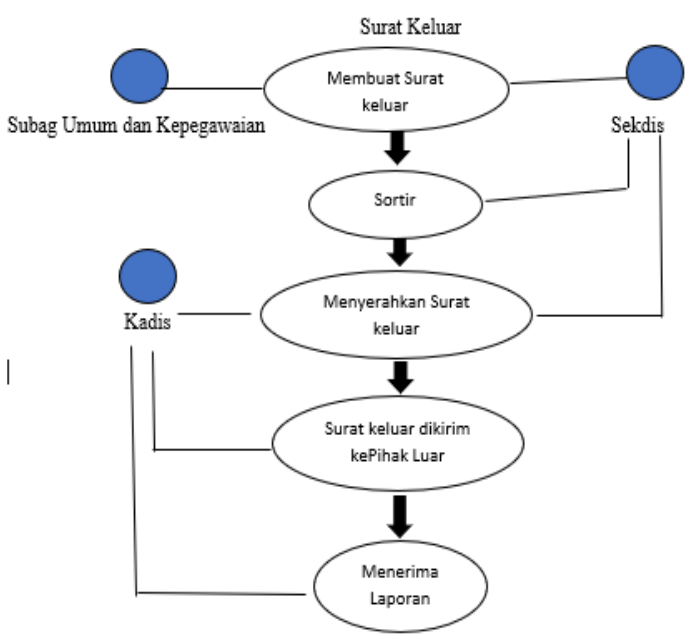

Gambar 2. Use Case Diagram Surat Keluar

Gambar 2 menunjukkan urutan dan unsur-unsur dalam Use Case Diagram surat keluar yang berjalan pada kondisi saat ini antara lain sebagai berikut, yakni:

1. Satu keseluruhan sistem yang meliputi semua rangkaian pelaporan surat keluar di Kantor Dinas Kesehatan Kota Puruk Cahu, Kabupaten Murung Raya, Provinsi Kalimantan Tengah.

2. Terdapat tiga aktor yang terlibat dalam kegiatan pengarsipan surat keluar yaitu subag umum, sekdis, dan kadis.

3. Terdapat tiga tahapan use case yang dikerjakan oleh ketiga aktor yaitu menyusun laporan buku surat masuk-keluar, meng-input data, menggabungkan data, melakukan audit arsip, menerima dan mengesahkan laporan pengarsipan. 
Procedia of Engineering and Life Science Vol. 1. No. 2 Juni 2021

Seminar Nasional \& Call Paper Fakultas Sains dan Teknologi (SENASAINS 2nd)

Universitas Muhammadiyah Sidoarjo

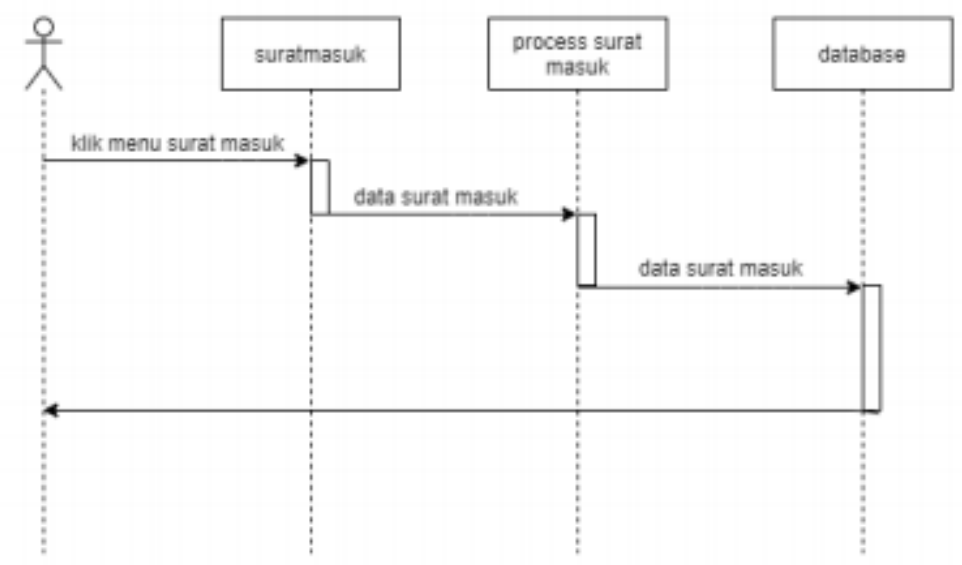

Gambar 2. sequence diagram proses surat masuk

Sequence diagram pengajuan surat keluar

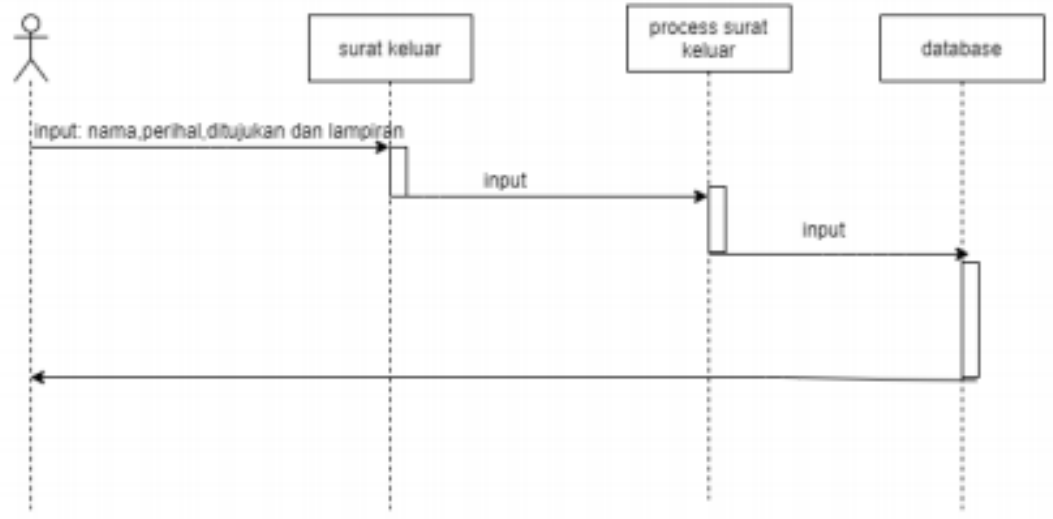

Gambar 3. sequence diagram pengajuan surat keluar

Sequence diagram dibuat sebanyak usecase diagram, sequence diagram pendisposisian surat masuk yang dilakukan oleh Kadis ke tujuan surat.

Activity diagram surat masuk

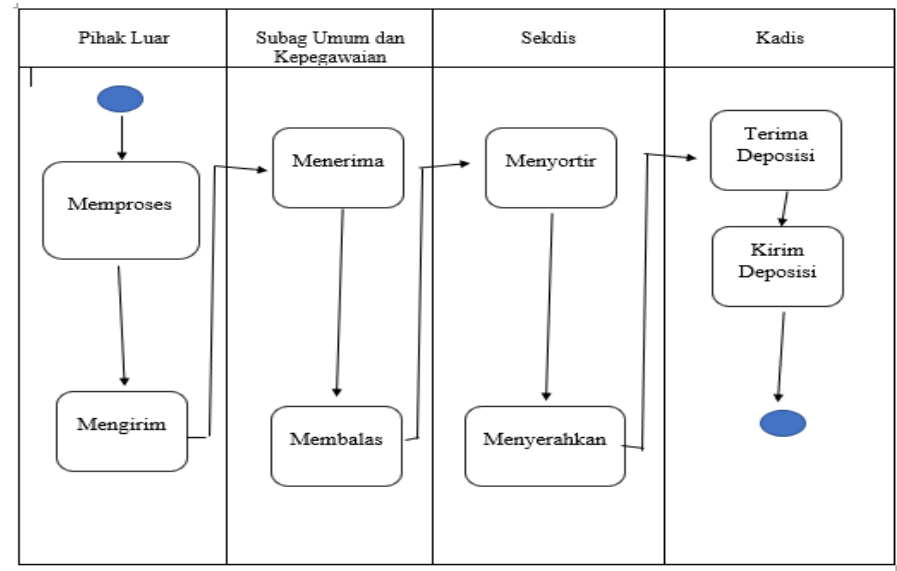

Gambar 4. Activity Diagram Surat Masuk

Gambar 4 menunjukkan Activity Diagram surat masuk yang berjalan saat ini yang mencakup hal-hal sebagai berikut, yakni:

1. Terdapat satu initial node yang mengawali objek.

2. Dalam activity diagram terdapat 8 stage, nilai atribut dan nilai link pada kurun waktu tertentu, spasi yang dimiliki objek tersebut. 
Procedia of Engineering and Life Science Vol. 1. No. 2 Juni 2021

Seminar Nasional \& Call Paper Fakultas Sains dan Teknologi (SENASAINS 2 ${ }^{\text {nd }}$ )

Universitas Muhammadiyah Sidoarjo

3. Satu activity final node menunjukkan bahwa objek telah terbentuk.

4. Dua buah vertical swimlace yang direpresentasikan oleh bentuk kotak.

5. Satu buah decision.

Activity diagram surat keluar

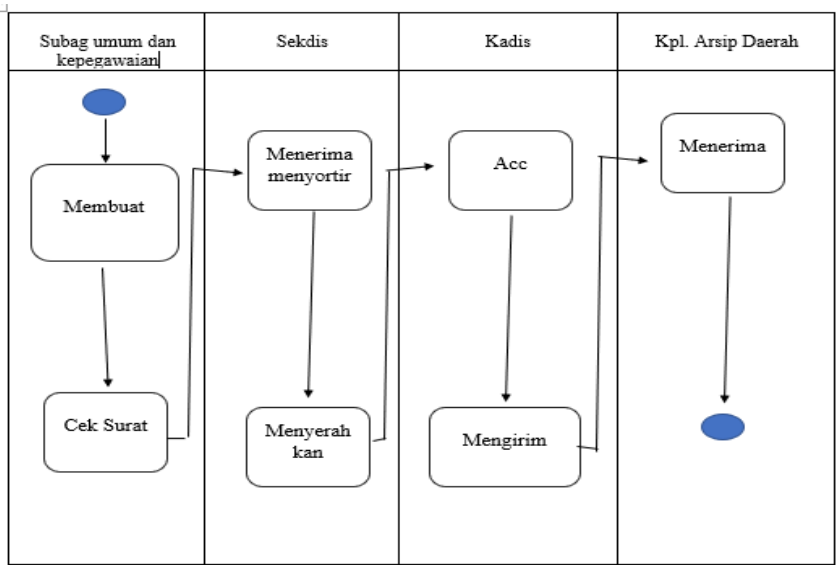

Gambar 5. Activity Diagram Surat Keluar

Gambar 5 menunjukkan Activity Diagram surat keluar yang berjalan saat ini yang mencakup hal-hal sebagai berikut, yakni:

1. Terdapat satu initial node yang mengawali objek.

2. Terdapat 7 stage, nilai atribut dan nilai link pada kurun waktu tertentu, spasi yang dimiliki objek tersebut.

3. Satu activity final node menunjukkan bahwa objek telah terbentuk.

4. Dua vertical swimlane objek yang direpresentasikan oleh bentuk kotak.

5. Satu decision.

\section{B. Analisa masalah}

Permasalahan yang dihadapi pada sistem yang sedang berjalan saat ini antara lain sebagai berikut :

a. Sistem ini menggabungkan proses pengarsipan konvensional dengan proses digital menggunakan komputer sehingga apabila terjadi kesalahan tentu akan sulit untuk merunut dan mencari awal mula kesalahan pencatatan dalam pengarsipan, hal ini pastinya akan mempersulit dan memperlambat durasi waktu proses pengambilan keputusan.

b. Sistem pelaporan akan memakan waktu lama dan memerlukan banyak pegawai, fenomena ini menyebabkan lamanya mendapatkan informasi yang dibutuhkan untuk mengambil keputusan.

\section{Pemecahan masalah}

Adanya kelemahan dari sistem pengarsipan manual mendorong peneliti untuk mencari solusi perbaikan bagi sistem pengarsipan agar mampu menjalankan fungsinya secara efektif dan efisien. Solusi yang dirawarkan antara lain:

a. Adanya sistem pengarsipan yang terintegrasi yaitu dengan menggunakan database berisi informasi yang diperlukan sesuai dengan kebutuhan menggunakan komputer sehingga pencatatan dilakukan secara digital.

b. Pemeriksaan dan audit dari kasubag dilakukan secara rutin dan periodik misalnya setiap seminggu sekali secara detail dan teliti sehingga apabila terdapat kesalahan atau kekurangan dapat diperbaiki secepatnya dan akan memudahkan pekerjaan pegawai.

\section{Aplikasi perancangan}

Terdapat berbagai pilihan untuk manajemen pernacangan sistem informasi pengarsipan. Contoh sederhananya adalah dengan menggunakan Microsoft Access untuk menginput dan memanajemen database. Selain itu, terdapat pula aplikasi Perancangan Pengarsipan Surat Menyurat dan Disposisi menggunakan Framework Codeigniter sebagai desain tampilan halaman web dan untuk penyimpanan data menggunakan Database MySQL. Semua surat masuk dan surat keluar yang akan diarsipkan akan di-scan terlebih dahulu dalam format gambar JPG atau format dokumen PDF sebelum disimpan dan diarsipkan sehingga ada bukti berupa softfile yang tersimpan dalam database.

\section{KESIMPULAN}

Sistem pengarsipan yang dilakukan di Kantor Dinas Kesehatan Kota Puruk Cahu saat ini masih bersifat konvensional atau manual sehingga memerlukan waktu lama agar laporan pengarsipan tersebut mampu berjalan dengan efektif dan efisien termasuk dalam hal penyimpanan dan pencarian arsip. 
Procedia of Engineering and Life Science Vol. 1. No. 2 Juni 2021

Seminar Nasional \& Call Paper Fakultas Sains dan Teknologi (SENASAINS 2nd)

Universitas Muhammadiyah Sidoarjo

Perlu adanya perbaikan sistem pengarsipan di Kantor Dinas Kesehatan Kota Puruk Cahu yaitu menerapkan sistem pengarsipan secara digital menggunakan komputer sehingga terdapat bukti dalam bentuk soft file dan database.

\section{UCAPAN TERIMA KASIH}

Penyusunan artikel ini tidak terlepas dari dukungan dan bantuan berbagai pihak. Peneliti ingin mengucapkan terima kasih atas dukungan, bimbingan, petunjuk dan bantuan serta dorongan dari berbagai pihak baik berupa dukungan moral maupun material. Pada kesempatan ini penulis ingin menyampaikan rasa terima kasih kepada:

1. Dr. Suria Siri., selaku Kepala Dinas Kesehatan Kota Puruk Cahu.

2. Murjani Thamrin, selaku kepala bidang Kepegawaian dan Umum Dinas Kesehatan Kota Puruk Cahu.

\section{REFERENSI}

[1] Badan Penyusun Rencana Kegiatan dan Anggaran, "Pentingnya Kearsipan bagi Organisasi atau Lembaga", Dinas Kelautan dan Perikanan Jawa Timur, 2020.

[2] G. P. Sari, J. Marzal, dan M. Mauladi, "RANCANG BANGUN SISTEM INFORMASI PERSURATAN DAN DISPOSISI ELEKTRONIK UNIVERSITAS JAMBI,” J. Sains dan Sist. Inf., vol. 1, no. 1, hal. 20-29, 2018.

[3] Mulyati, M., Sany, N., \& Kurniawan, M. (2020). Sistem Informasi Surat Masuk Pada Pengelolaan Rantai Suplai Satuan Kerja Khusus Migas. Technomedia Journal, 5(1), 27-39. https://doi.org/10.33050/tmj.v5i1.1256

[4] C. Puspasari, Durinda; Nikmah, "Effectiveness of Archive Management on Record System in National Zakat Agency in Indonesia," in 2nd Social Sciences, Humanities, and Education Conference (SoSHEC 2018), 2018, hal. 283-288.

[5] Pawana, M. G., Suharsono, N., \& Kirna, I. M. (2014). Pengembangan Multimedia Interaktif Berbasis Proyek Dengan Model ADDIE Pada Materi Pemrograman Web Siswa Kelas X Semester Genap Di SMK Negeri 3 Singaraja. E-Journal Program Pascasarjana Universitas Pendidikan Ganesha

[6] Anggraeni, D., \& Iriani, S. (2013). Sistem Informasi Pengarsipan Surat Masuk Dan Surat Keluar Pada Kantor Kecamatan Pringkuku. Indonesian Journal on Networking and Security.

[7] Sri Ardiana dan Bambang Suratman, "Pengelolaan Arsip Dalam Mendukung Pelayanan Informasi Pada Bagian Tata Usaha di Dinas Sosial Kabupaten Ponorogo," Jurnal Pendidikan Administrasi Perkantoran (JPAP), vol. 9, no. 2, hal 8, 2021

[8] Basri, \& Devitra, J. (2017). Analisis Dan Perancangan Sistem Informasi Pengelolaan Arsip Berbasis Web (Studi Kasus: Pada Komisi Pemilihan Umum (Kpu) Kabupaten Tebo. Jurnal Manajemen Sistem Informasi, 2(1), 227243

[9] Wati, M., \& Despahari, E. (2018). Sistem Informasi Pelayanan Administrasi Kependudukan Dan Catatan Sipil Kelurahan Di Kecamatan Marangkayu Kutai Kartanegara. Jurnal Rekayasa Teknologi Informasi.

[10] Anggraeni, Defi dan Iriani, Siska. 2013. Sistem Informasi Pengarsipan Surat Masuk Dan Surat Keluar Pada Kantor Kecamatan Pringkuku. IJNS-Indonesian Journal on Networking and Security. 